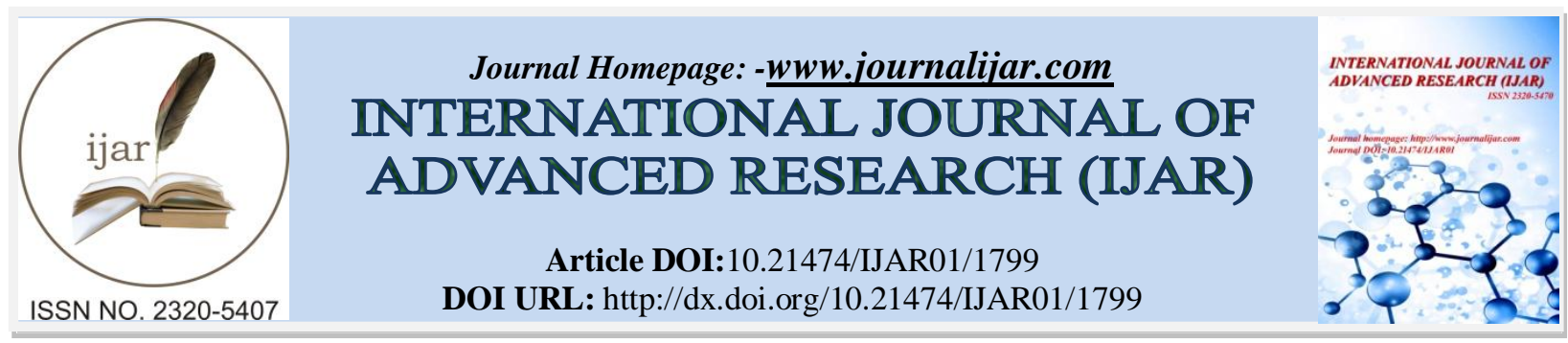

RESEARCH ARTICLE

\title{
INVESTIGATED THE IMPACT OF PRICE ON CONSUMER BUYING DECISION BEHAVIOR OFCOMPULSIVE BUYING.
}

\author{
Shakeri Sara ${ }^{1}$ and Soleymani Mohammad Hossein ${ }^{2 *}$. \\ 1. $\mathrm{PhD}$ of Marketing Management, Department of Business Management, Science and Research Branch, Islamic \\ Azad University, Tehran, Iran. \\ 2. Master's Student of the Marketing Management, Molana Institute of Higher Education (Qazvin,Iran).
}

\section{Manuscript Info}

Manuscript History

Received: 12 August 2016

Final Accepted: 13 September 2016

Published: October 2016

Key words:-

Compulsive buying, Price knowledge,

Price consciousness, Brand preferences,

Purchase behavior.

\section{Abstract}

The main reason for this study was investigation of influential price factors on consumer decision behavior of compulsive buyer. This study was conducted to develop a better understanding of consumer buying decision behavior of compulsive buying' perspective and examines the relationship of price role and identify factors affecting. The new point of this study was to identify the impact of price factors on compulsive buying behavior between university students.Since identification of consumer behavior can improve business, factors obtained in this studysuch as price consciousness, sale proneness and transaction value were more effective on compulsive buying behavior.

Copy Right, IJAR, 2016,. All rights reserved.

\section{Introduction:-}

Formulation of the problem generally:All businessmen want to achieve success in their business. One key to success is attention to all aspects of consumer behavior. There remain many empty gaps in research compulsive buying. Also, cultural factors affect the purchase process is certainly less research to date has taken on the role of education in compulsive buying. So, this is a fascinating new topic in consumer behavior that, are expected to be large numbers of people involved with it. More research scientists intend to examine the reasons for compulsive buying that men or women are more involved in this process and what factors might affect the compulsive buying.According to various aspects of consumer behavior, we try to identify what factors can have an even greater impact on consumer behavior, compulsive buying andbetter use of these factors in our business process.

Analysis of recent researches and publications:Compulsive buying was a favorite subject of consumer behavior researchers and a policy popular in United States and other developed countries for over two decades (Koran et al., 2006; Neuner et al., 2005; Müller et al., 2004). Compulsive buying is perceived as consumer sentiment to entertain themselves with shopping. It is shown that by buying repeated in a way that cannot control their desire to purchase (Ridgway et al., 2008).Logical reason that compulsive buying is classified as an obsessive-compulsive thoughts consumer is intrigued shopping, such as obsessive compulsive and repetitive behavior purchases to reduce the anxiety that person (McElroy et al., 1994). Studying on previous research on compulsive buying, we first outline some of the main characteristics of compulsive buyers. First, the behavior is more likely to affect female than male since it has been estimated that 80-92 \% of compulsive buyers are female (Black and DonaldW, 1996; Faber et al., 1995; Faber et al., 1989). Second, although there is some historical evidence of compulsive buying happening in the early 1900s, the documentation of this phenomenon appears to be more recent (Faber and Ronald J, 1992). Number

Corresponding Author:-Soleymani Mohammad Hossein.

Address:-Master's Student of the Marketing Management, Molana Institute of Higher Education, Abyek 
of scholar believe this recent advent of compulsive buying may be dependent on increased emphasis on and availability of material possessions in our consumer culture (Hirschman and Elizabeth C, 1992; Richins et al., 1992). Third, Consumer behavior researchers believe that when people want to use your products to demonstrate to others. (Who We Are)(Krueger and David W, 1988; Belk and Russell W, 1988; Hirschman and Elizabeth C, 1995). Thus, an addiction to buying goods may be a search for one's self much more than other compulsive behaviors, such as drinking, gambling, under or over eating, or using drugs (Belk and Russell W, 1988; Friese and Susanne, 2000). Also, compulsive buyers are probable that buy more than what they can afford and difficulties experienced credit card (Roberts et al., 2002). Moreover, Compulsive buyers are more likely purchase process with guilt and shame experience. So buying and purchasing activity to hide from others (Ridgway et al., 2008). Purchaser with emotions of insecurity and low self-esteem may try to compensate to make themselves feel more deserving.One way to provisionally enhance their self-esteem is to purchase things for themselves. Because of their lower self-esteem, most woman compulsive buyers tend to purchase clothing and accessories primarily for themselves to raise their self-esteem and enhance their self-image to a greater degree than non-compulsive buyers (Roberts et al., 2002; McElroy et al., 1994).We would expect compulsive buyers to be more focused on buying famous national brands as opposed to lesser known or store brands. Whilebrand awareness as a buyer characteristic may not be directly related to price, nevertheless, famous and national brands are almost priced higher than less known store brands (Eitan Gerstner et al., 2003; Dick et al., 1997). Purchaser culture, people have been supposed to experience after 1980, is specific as a culture in which the large majority of purchaser desire, purchase and use products and services to become a good member of this culture. Thus, especially in wealthy countries, purchaser spending has already exceeded disposable revenue(Roberts et al., 2001). Because extreme shopping has caused individuals lives to go out of a control(Ureta, I.G, 2007).

\section{Theoretical background and hypothesis development:-}

Sale proneness, as an increasing tendency to respond to an offer for a lower price is defined due to sales form in which the price offered(Lichtenstein et al., 1993). Sale signs drawing attention and desires of the shoppers(Inman et al., 1990). States, consumers who are prone to sell more likely to perceive a higher value when the purchase price compared with the price of a sale form is not provided in the form of sales(Inman et al., 1990; Lichtenstein et al., 1993).Compulsive buyers may be to find a sales reward (While not necessarily deliberately followed one) by buying more. Buy to offer an excuse for buying them, and at the same time reduce guilt buyers in connection with the purchase(Faber et al., 1992). In addition, to obtain the sales price on a product that may be a source of extra excitement and enjoyment for the consumer, allowing them to increase enjoy the benefits of finding a sales. As mentioned, the experience of positive emotions during the buying process is very important to compulsive buyers (Faber et al., 1989).

H1. There is a direct relationship between sale proneness and compulsive buyers.

We suggest that compulsive buyers will be get a good deal more than the value of transactions in their shopping compared to non-compulsory buyers understand. Because of its focus on obtaining low prices and their willingness to respond to sales and promotion, to get a good deal should be important to them. In addition, key features compulsive buyers is that they are trying to experience positive emotions that can be extracted buying process.Compulsive buyers love the act of purchase and for a period of time (usually short) purchase make them happy (Aboujaoude et al., 2003). Another reason is that a good financial deal can be purchased forced an excuse to buy, allowing them to quickly satisfy their desire to purchase, while at the same time reducing the strong emotions of guilt that are often after purchase experienced(Faber et al., 1992). Lastly, completing the deal value must be more for compulsive buyers, as their focus is on actually buying, and not only purchase.

H2. There is a direct relationship between perceived transaction value from a price promotion and compulsive buyers.

Compulsive buyers are experienced buyers who are able to gather extensive knowledge of the product during the period of frequent shopping trips than they have been (Kukar-Kinney et al., 2009). They should have enough knowledge to assess the quality of the goods in a timely manner without having to spend considerable effort will have to reach a purchase decision. So, rather aware, compulsive buyers should not need to rely on price as an indicator of quality as well as non-compulsory less experienced buyers(Ofir et al., 2008; Rao et al., 1988).Before deciding to buy, consumers may need to invest time and effort to get enough information to make an accurate and informed assessment of the product, its benefits, and alternatives. When sufficient time is not available or when there is little incentive to carefully assess, consumers may heuristics that rely on them in the decision-making process. When the price used in this role, there will be a positive relationship between price and perceived value on 
the one hand, and the purchase intentions of the other.It is shown that consumers are likely to use price-quality discoveries in situations when they don't have enough time to evaluate options or when they do not have enough knowledge to judge the quality (Rao et al., 1988; Suri et al., 2003).

H3. There is a direct relationship between price-quality inferences and compulsive buyers.

Found that compulsive buyers have lower self-esteem than others (D'Astous and Alain, 1990; Dittmar et al., 2000; Faber et al., 1992). Prestige sensitivity to the feelings and beliefs of buyers that high commodity prices will signal to others that the buyer has a high level of prestige and status (Aboujaoude et al., 2003). Research has shown a positive relationship between tendency compulsive buying and interest fashion (Park et al., 2005).Since the compulsive buyers self-esteem is low, we can expect that they should be more likely to buy prestigious products. Buy prestigious products can help to increase their understanding of the goals and facilitate consumers in their value and complete their value(Belk and Russell W, 1988).

H4. There is a direct relationship betweenprestige sensitivity and compulsive buyers.

Experience positive emotions, such as pleasure shopping, an important part of the process of buying for compulsive buyers (Faber et al., 1992). They have something more pleasurable experience when they buy National as Compared to store brands, lead them to prefer national brand stores. As sensitive to prestige, compulsive buyers are more likely to receive increase confidence when they purchase (and consequently use it) well-known high price brands (Ailawadi et al., 2001).This idea is true for apparel brands as well (for example Zara a store brand is more expensive than Gerad).

H5.There is a direct relationship between brand consciousness and compulsive buyers.

The consumer is not aware of the price, get a low price for her product selection is less important than the consumer price consciousness(Alford et al., 2002).Two basic theory is that from an economic standpoint about prices, buyers are paying the minimum price to buy, and those who have knowledge price is about the lowest price they want (Lichtenstein et al., 1993; Lichtenstein et al., 1988). Buy too often negative financial consequences involved, such as severe debt credit card(Faber et al., 1992).Low prices can also better enable them to experience greater hedonic benefits of shopping(Brenda Sternquist et al., 2003).

H6. There is a direct relationship betweenprice consciousness and compulsive buyers.

A specification of purchaser who exhibit high compulsive buying orientation is their greater frequency of shopping and buying as well as spending more on their shopping in compare with costomers with lower compulsive buying orientation(Kukar-Kinney et al., 2009).Prior research is obscure about how much consumers in total are informed and knowledgeable of prices in the shops and across stores(Monroe and Kent B, 2003; Vanhuele et al., 2002). Because of their repeated and extensive buying and purchase episodes, compulsive buyers can be able to stack greater exposure to price information and become more knowledgeable about shops' prices in compare with non-compulsive buyers during the time. Also, due to their extensive shopping experience, they should consider themselves to be more knowledgeable.Therefore, we recommend that:

H7. There is a direct relationship between store price knowledge and compulsive buyers.

\section{Methodology:-}

Research Goal:-In this research, investigate the relationship between the role of price and the purchase decision of consumers in the compulsive buying is amid.

Sample and Data Collection:- To examine the hypotheses, comprehensive survey was conducted among Molana university students. At first we were a notification among all the students that their number was 1450.In the next step, we could give surveys to 1230 students. Technical problems reduced the final number of potential people who participated in the survey.816 people were removed, and 414 people participated in the survey correctly, resulting in a response rate of 33.4 percent. 63 percent of respondents woman, and 37 percent were male.Their mean age was 21 years(range 18-32 years). The survey questions were about: buying behavior, compulsive buying,consumer personal characteristics, demographic and response to price.

Measures:The main reason for doing this research in a university setting is that more research is done in the field of management science at the university.To measure the tendency of people to buy compulsive, we used 7 item compulsive buing scale how recently developed.Compulsive buying structure is perceived of two dimensions: impulsive buying and compulsive preoccupation with buying. We formed an index of compulsive buying and using a 5-point Likert-frequency collected answers and the answers were tested by the test Baxsplot to find errors (see 
figure 1).we were measured, all price related constructs with multiple items. Most items were taken from the previous literature and some were developed and added to existing items in this research.Cronbach's alpha was calculated for each variable and all of them were above 7.5. Then we identify the missing data and replacing them with Median.

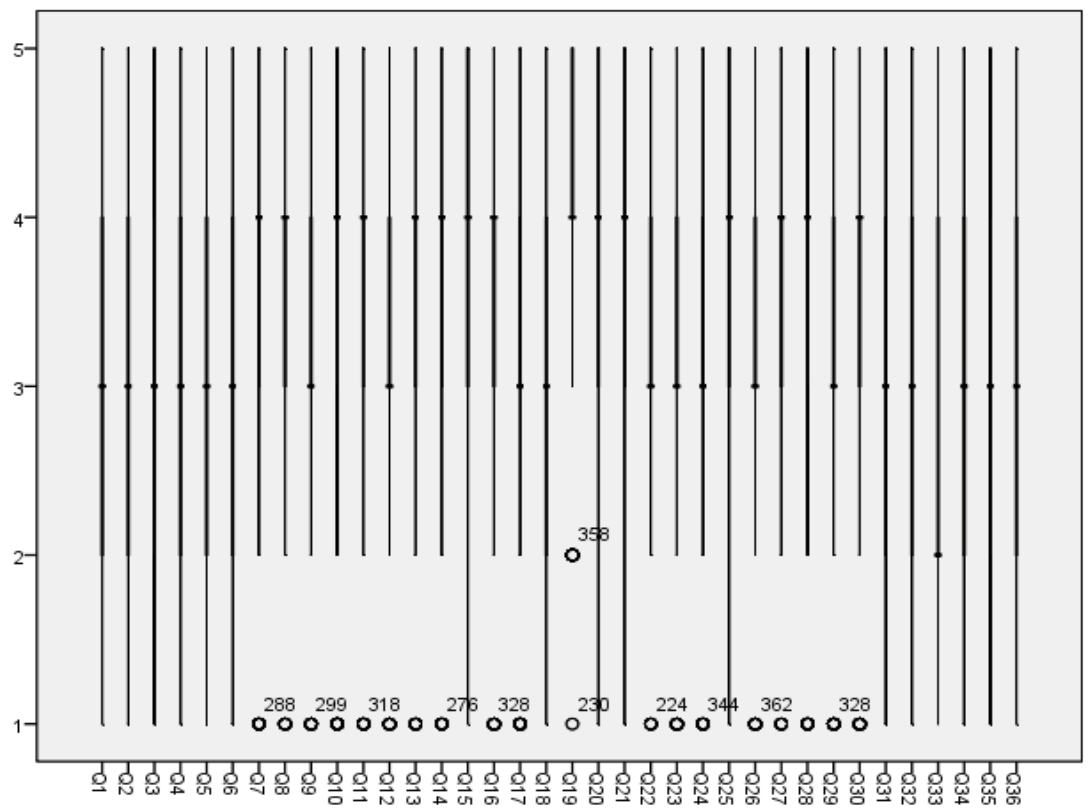

Figure 1:- _ Boxplot test

To test the sufficient of the volume of data, KMO and Bartlett's Test was used (see table 1).For normal testing, the skewness and kurtosis were used.The primary method for model testing was structural equations modelling by means of LISREL 8.73 . Ordinary Least Squares was used as the model estimation method due to using ordinal scales for measurement (J reskog et al., 1996).

Table 1:- KMO and Bartlett's Test.

\begin{tabular}{|l|l|l|}
\hline Kaiser-Meyer-Olkin Measure of Sampling Adequacy. & .880 \\
\cline { 2 - 3 } Bartlett's Test of Sphericity & Approx. Chi-Square & $9.218 \mathrm{E} 3$ \\
\cline { 2 - 3 } & df & 630 \\
\cline { 2 - 3 } & Sig. & .000 \\
\hline
\end{tabular}

\section{Analysis and Results:-}

In order to test of Hypothesis we conducted structural equation modeling (SEM) analyses. The model for these analyses included seven exogenous latent factors, price consciousness, store price knowledge, sale proneness, transaction value, price-quality inference, prestige sensivity and brand consciousness.Finally, the hypothesized model also includes one latent endogenous factors, compulsive buying. The fit of the models was assessed with the 2 statistic, the Goodness- of-Fit Index (GFI), and the root mean square error of approximation (RMSEA). In addition, we used the Comparative Fit Index (CFI), the Incremental Fit Index (IFI), and the Non-Normed Fit Index (NNFI). For each of these statistics, values of 0.90 or higher are acceptable (Hoyle and R. H, 1995), except for the RMSEA for which values up to 0.08 indicate an acceptable fit to the data(MacCallum et al., 1996). Furthermore, we controlled for the $90 \%$ confidence intervals around the RMSEA. A narrow confidence interval is an indication for good precision of the RMSEA(MacCallum et al., 1996). As noted, all constructs were assessed using 5-point Likert type scales.

\section{Descriptive Results, Measurement Model and Convergent validity:-}

As can be seen from Table 2, it can be seen that the values in the diagonals are greater than the values in their respective row and column thus indicating the measures used in this study are distinct. Reliability combined average variance extracted for assessment of convergent and divergent validity. (see table2). Composite reliabilities range from 0.88 (for Price consciousness) to 0.873 (for Price-quality inference), which exceed the recommended level of 
0.7, (see table 1), therefore, demonstrate a reasonable reliability level of the measured items. We used the factor loadings (see table3), the recommended values for loadings are set at $>0.5$. From table 2 it can be seen that the results of the measurement model exceeded the recommended values thus indicating sufficient convergence validity.

Table 2:- loading factors AVE, ASV, CR and MSV.

\begin{tabular}{|l|l|l|l|l|}
\hline Construct & AVE & ASV & CR & MSV \\
\hline Compulsive buying & 0.593 & 0.094 & 0.905 & 0.144 \\
\hline Price consciousness & 0.603 & 0.066 & 0.88 & 0.16 \\
\hline Store-price knowledge & 0.605 & 0.112 & 0.822 & 0.16 \\
\hline Sale proneness & 0.657 & 0.452 & 0.851 & 0.533 \\
\hline Transaction value & 0.606 & 0.074 & 0.815 & 0.073 \\
\hline Price-quality inference & 0.534 & 0.106 & 0.873 & 0.27 \\
\hline Prestige sensitivity & 0.546 & 0.278 & 0.877 & 0.756 \\
\hline Brand consciousness & 0.667 & 0.513 & 0.855 & 0.756 \\
\hline
\end{tabular}

Table 3:- Descriptive Statistics, Bivariate Correlations.

\begin{tabular}{|l|l|l|l|l|l|l|l|l|}
\hline Construct & CB & PC & SPK & SP & TV & PQI & PS & BC \\
\hline Compulsive buying & 1.01 & & & & & & & \\
\hline Price consciousness & 0.28 & 1.00 & & & & & & \\
\hline Store-price knowledge & 0.20 & 0.40 & 1.00 & & & & & \\
\hline Sale proneness & 0.36 & 0.07 & 0.19 & 1.00 & & & & \\
\hline Transaction value & -0.05 & 0.24 & 0.27 & 0.26 & 1.00 & & & \\
\hline Price-quality inference & 0.29 & 0.07 & 0.13 & 0.35 & -0.06 & 1.00 & & \\
\hline Prestige sensitivity & 0.38 & 0.15 & 0.07 & 0.68 & 0.11 & 0.52 & 1.00 & \\
\hline Brand consciousness & 0.30 & 0.05 & 0.07 & 0.73 & 0.09 & 0.37 & 0.87 & 1.00 \\
\hline
\end{tabular}

Construct reliabilities are displayed on the diagonal, construct inter-correlations obtained are reported below the diagonal

Goodness of fit statistics:The primary method for model testing was structural equations modeling by means of LISREL 8.73 and the polychromic correlation matrix as input. Ordinary Least Squares was used as the model estimation method due to using ordinal scales for measurement (J reskog et al., 1996).This testing confirms a model's goodness of fit, and the hypothesized paths. Results of SEM analysis showed that model fits well to the data.(see table 4),

Table 4:- Goodness of Fit Statistics.

\begin{tabular}{|l|l|l|l|l|l|l|l|l|l|l|}
\hline Modification & Chi-Square/DF & RMSEA & PNFI & GFI & AGFA & NFI & NNFI & RFI & IFI & CFI \\
\hline Before Modification & 2.88 & 0.068 & 0.83 & 0.82 & 0.79 & 0.92 & 0.94 & 0.91 & 0.95 & 0.95 \\
\hline After Modification & 2.53 & 0.061 & 0.82 & 0.84 & 0.81 & 0.93 & 0.95 & 0.92 & 0.96 & 0.96 \\
\hline
\end{tabular}

Structural Model:-As shown in Table 5. To evaluate the structural models' predictive power, we calculated the $\mathrm{R}^{2}$, $\mathrm{R}^{2}$ indicates the amount of variance explained by the exogenous variables(Barclay et al., 1995).Using a T-value technique with a sampling of 414, the path estimates and t-statistics were calculated for the hypothesized relationships.Four hypotheses were not supported in the testing (the effect of store-price knowledge on compulsive buying, the effect of price-quality inference on compulsive buying, the effect of prestige sensitivity on compulsive buying and the effect of brand consciousness on compulsive buying). 2 hypotheses were supported in the testing at $\mathrm{P}<0.01$ and 1 hypotheses were supported in the testing at $\mathrm{P}<0.05$ : As shown in Table 5the path coefficients ant result of hypotheses. As shown in Table 5. To evaluate the structural models' predictive power, we calculated the $\mathrm{R}^{2}$, $\mathrm{R}^{2}$ indicates the amount of variance explained by the exogenous variables(Barclay et al., 1995).

Table 5:- Result of hypotheses test .

\begin{tabular}{|l|l|l|l|l|l|}
\hline Hypothesis & T-value & Beta & $\mathrm{R}^{2}$ & Result & Sign \\
\hline Price consciousness $\rightarrow$ Compulsive buying & 3.77 & 0.23 & & Supported & + \\
\hline Store-price knowledge $\rightarrow$ Compulsive buying & 1.56 & 0.10 & & NS & NS \\
\hline Sale proneness $\rightarrow$ Compulsive buying & 3.24 & 0.30 & & Supported & + \\
\hline
\end{tabular}




\begin{tabular}{|l|l|l|l|l|l|}
\hline Transaction value $\rightarrow$ Compulsive buying & -3.77 & -0.22 & $\% 27$ & Supported & - \\
\hline Price-quality inference $\rightarrow$ Compulsive buying & 0.78 & 0.5 & & NS & NS \\
\hline Prestige sensitivity $\rightarrow$ Compulsive buying & 1.70 & 0.29 & & NS & NS \\
\hline Brand consciousness $\rightarrow$ Compulsive buying & 1.11 & -0.19 & & NS & NS \\
\hline$|t|>1.96$ Significant at $P<0.05,|t|>2.58$ Significant at $P<0.01$, & \\
\hline
\end{tabular}

\section{Conclusions and directions of further researches:-}

Considering that the customer return to the company for the purchase is one of the most demanding business executives and given that demographic factorssuch as level of education of each person can change what price factors affect on compulsive behavior. Due to the efforts to identify the influential factors prices on compulsive buying in a study in 2012 by Monika Kukar-Kinney et al(Monika Kukar-Kinney., 2012) and taking into account the studies that EstíbalizVillardefrancos in 2016 (EstíbalizVillardefrancos and José Manuel Otero-López, 2016) were among the students about the prevalence of compulsory buying, we decided to do this study. The current study examines the relationship between the role of price and the purchase decision of consumers in the compulsive buying. This study will not only assist managers on identifying these kind of consumer, but it will also develop the available knowledge on how to explore the role of these factors. According to the hypothesis, the price consciousness has an impact on compulsive buyers. So one of the influential factors on Compulsive-buyers behavior is Price-consciousness that marketers should pay more attention to while pricing goods. The next variable is sale proneness, which affectson compulsive buyer.The result showed that the Sale-proneness has positive effect on Compulsive-buyer behavior.Other variables that affect on compulsive buyer is transaction value. This point is completely clear when consumers want to buy any goods, they pay more attention to Transaction-value. As the results showed that this type of customers are just like other customers and when the Transaction-value is high, they will be pleased. This factor makes them feel good to repeat purchase their own. Other variables in the study, such as: store-price knowledge, price-quality inference, prestige sensitivityand brand consciousness about compulsive buyers is not supported.Concerning directions of farther researches: Further investigation and experimentation into identify other factors affecting on compulsive buying is strongly recommended. This research was conducted on students in the academic environment. Only further research can specify who this result can be replicated in other populations and contexts, as this research is restricted to the university students and relies on survey data from individuals. Future studies are recommended to be investigated in other environments.

\section{References:-}

1. Aboujaoude, E., N. Gamel and Lorrin Koran (2003), "A 1-Year Naturalistic Follow-Up of Patients with Compulsive Shopping Disorder," Journal of Clinical Psychiatry, 64 (8), 946-50.

2. Ailawadi, Kusum L., Scott A. Neslin and Karen Gedenk (2001), "Pursuing the Value Conscious Consumer: Store Brands Versus National Brand Promotions," Journal of Marketing, 65 (January), 71-89.

3. Alford, Bruce L. and AbhijitBiswas (2002), "The Effects of Discount Level, Price Consciousness and Sale Proneness on Consumers' Price Perception and Behavioral Intention," Journal of Business Research, 55 (9), 775-83.

4. Black, DonaldW. (1996), “Compulsive Buying: A Review,” Journal of Clinical Psychiatry, 57 (8), 50-5.

5. Belk, Russell W. (1988), "Possessions and the Extended Self," Journal of Consumer Research, 15 (September), 139-68.

6. Benson, April Lane (2000), I Shop Therefore I Am: Compulsive Buying and the Search for Self, New York, NY: Aronson.

7. Brenda Sternquist, Jin Byoungho, and AeranKoh (2003), "Price as Hedonic Shopping," Family and Consumer Sciences Research Journal, 31 (4), 378-402.

8. Barclay, D. W., Thompson, R., \& Higgins, C. (1995). The Partial Least Squares (PLS) Approach to Causal Modeling: Personal Computer Adoption and Use an Illustration. Technology Studies, 2(2), 285-309.

9. D'Astous, Alain (1990), "An Inquiry into the Compulsive Side of Normal Consumers," Journal of Consumer Policy, 13 (March), 15-31.

10. Dittmar, Helga and John Drury (2000), "Self-Image-Is It In the Bag? A Qualitative Comparison between 'Ordinary' and 'Excessive' Consumers,' Journal of Economic Psychology, 21 (2), 109-42.

11. Dick, Alan, Arun Jain and Paul Richardson (1997), "How Consumers Evaluate Store Brands," Pricing Strategy \& Practice, 5 (1), 18-24.

12. Eitan Gerstner and Prasad A. Naik, Apelbaum, Eidan (2003), "The Effects of Expert Quality Evaluations versus Brand Name on Price Premiums," Journal of Product and Brand Management, 12 (2/3), 154-65. 
13. EstíbalizVillardefrancos and José Manuel Otero-López (2016), "Compulsive buying in university students: its prevalence and relationships with materialism, psychological distress symptoms, and subjective well-being” Comprehensive Psychiatry 65 (2016) 128-135.

14. Faber, Ronald J., Gary A. Christenson, Martina de Zwaan and James Mitchell (1995), "Two Forms of Compulsive Consumption: Comorbidity of Com pulsive Buying and Binge Eating," Journal of Consumer Research, 22 (December), 296-304.

15. Faber, Ronald J. and Thomas C. O’Guinn (1989), "Classifying Compulsive Consumers: Advances in the Development of a Diagnostic Tool," In Advances in Consumer Research, Vol. 16, Srull, Thomas ed. Provo, UT: Association for Consumer Research, 738-44.

16. Faber, Ronald J. (1992), "Money Changes Everything: Compulsive Buying from a Biopsychological Perspective," American Behavioral Scientist, 35 (6), 809.

17. Friese, Susanne (2000), A Self-Concept and Identity in a Consumer Society: Aspects of Symbolic Product Meaning, Marburg, Germany: Tectum.

18. Faber, Ronald J. and Thomas C. O’Guinn (1992), “A Clinical Screener for Compulsive Buying," Journal of Consumer Research, 19 (December), 459-6.

19. Fornell, C.,\&Lacker, D.F. (1981). Evaluation structural equation models with unobserved variables and measurement error. Journal of Marketing Research, 18(1), 39-50.

20. Hirschman, Elizabeth C. (1992), "The Consciousness of Addiction: Toward a General Theory of Compulsive Consumption," Journal of Consumer Research, 19 (September), 155-79.

21. Hirschman, Elizabeth C. (1995), "Professional, Personal, and Popular Culture Perspectives on Addiction (1995)," American Behavioral Scientist, 38 (4), 537.

22. Hair, J. F., Anderson, R. E., Tatham, R. L., \& Black, W. C. (1998).Multivariate data analysis. New Jersey: Prentice-all.

23. Hu, L., \&Bentler, P. M. (1999). Cut-off criteria for fit indexes in covariance structure analysis: Conventional criteria versus new alternatives. Structural Equation Modelling, 6(1), 1-55.

24. Hair, J. F., Black, W. C., Babin, B. J., \& Anderson, R. E. (2010).Multivariate Data Analysis. Upper Saddle River, NJ: Prentice-Hall.

25. Hoyle, R. H. (1995). The structural equation modeling approach: Basic concepts and fundamental issues. In Structural equation modeling: Concept, issues, and applications, R. H. Hoyle (editor). Thousand Oaks, CA: Sage Publications, Inc., pp. 1-15.

26. Inman, Jeffrey, Leigh M. McAlister and Wayne D. Hoyer (1990), "Promotion Signal: Proxy for a Price Cut?," Journal of Consumer Research, 17 (June), 74-81.

27. J reskog, K. G., \&Sorbom, D. (1996).LISREL 8 user's reference guide. Chicago: Scientific Software International.

28. Koran, Lorrin, Ronald J. Faber, Elias Aboujaoude, Michael D. Large and Richard T. Serpe (2006), "Estimated Prevalence of Compulsive Buying Behavior in the United States," American Journal of Psychiatry, 163 (1), 1806-12.

29. Krueger, David W. (1988), “On Compulsive Shopping and Spending: A Psychodynamic Inquiry,” American Journal of Psychotherapy, 42 (4), 574-8.

30. Kukar-Kinney, Monika, Nancy M. Ridgway and Kent B. Monroe (2009), "The Relationship between Consumers' Tendencies to Buy Compulsively and Their Motivations to Shop and Buy on the Internet," Journal of Retailing, 85 (3), 298-307.

31. Lichtenstein, Donald R., NancyM. Ridgway and Richard G. Netemeyer (1993), "Price Perceptions and Consumer Shopping Behavior: A Field Study," Journal of Marketing Research, 30 (May), 234-45.

32. Lichtenstein, Donald R., Peter H. Bloch and William C. Black (1988), "Correlates of Price Acceptability," Journal of Consumer Research, 15 (2), 243-52.

33. Mathieu, J. E., Tannenbaum, S. I., \& Salas, E. (1992).Influences of individual and situational characteristics on measures of training effectiveness. Academy of Management Journal, 35, 828 - 847.

34. MacCallum, R. C., Browne, M. W., and Sugawara, H. M. (1996). Power analysis and determination of sample size for covariance structure modelling. Psychological Methods, 1, 130 -149.

35. Monika Kukar-Kinney, Nancy M. Ridgway and Kent B. Monroea (2012), "The Role of Price in the Behavior and Purchase Decisions of Compulsive Buyers" Journal of Retailing 88 (1), 63-71.

36. Müller, Astrid and Martina M. de Zwaan (2004), "Current Status of Psychotherapy Research on Pathological Buying," Verhaltenstherapie, 14 (2), 112-9.

37. McElroy, Susan, Katharine Phillips and Paul Keck (1994), “Obsessive Compulsive Spectrum Disorder,” Journal of Clinical Psychiatry, 55 (10), 33-5. 
38. Monroe, Kent B. (2003), Pricing: Making Profitable Decisions, 3rd ed. New York: McGraw-Hill/Irwin

39. Neuner, Michael, Gerhard Raab and Lucia Reisch (2005), "Compulsive Buying in Maturing Consumer Societies: An Empirical Re-Inquiry," Journal of Economic Psychology, 26 (4), 509-22.

40. Ofir, Chezy, PriyaRaghubir, GiliBrosh, Monroe S Kent B. and Amir Heiman (2008), "Memory Based Store Price Judgments: The Role of Knowledge," Journal of Retailing, 84 (December), 414-23.

41. Park, Hye-Jung and Leslie Davis Burns (2005), "Fashion Orientation, Credit Card Use, and Compulsive Buying," Journal of Consumer Marketing, 22 (3), 135-41.

42. Ridgway, Nancy M., Monika Kukar-Kinney and Kent B. Monroe (2008), "An Expanded Conceptualization and New Measure of Compulsive Buying," Journal of Consumer Research, 35 (4), 622-39.

43. Richins, Marsha L. and Scott Dawson (1992), "A Consumer Values Orientation for Materialism and Its Measurement: Scale Development and Validation," Journal of Consumer Research, 19 (December), 303-17.

44. Roberts, James A. and Eli Jones (2002), "Money Attitudes, Credit Card Use, and Compulsive Buying Among American College Students," Journal of Consumer Affairs, 35 (2), 213-40.

45. Rao, Akshay R. and Kent B. Monroe (1988), "The Moderating Effect of Prior Knowledge on Cue Utilization in Product Evaluations," Journal of Consumer Research, 15 (September), 253-64.

46. Roberts, J. A., \& Jones, E. (2001).Money attitudes, credit card use, and compulsive buying among American college student. The Journal of Consumer Affairs, 35, 213-240.

47. Suri, Rajneesh and Kent B. Monroe (2003), "The Effects of Time Constraints on Consumers' Judgments of Prices and Products," Journal of Consumer Research, 30 (June), 92-104.

48. Ureta, I.G, (2007); Addictive buying: Causes, processes and symbolic meanings. Thematic analysis of a buying addict's diary, The Spanish Journal of Psychology, Vol. 10 no.2, pp.408-422.

49. Vanhuele, Marc and Xavier Dreze (2002), "Measuring the Price Knowledge Shoppers Bring to the Store," Journal of Marketing, 66 (October), 72-85. 